\title{
BMJ Global Health What will it take to implement health and health-related sustainable development goals?
}

\author{
Zulfiqar Ahmed Bhutta (1) , , 2 Sameen Siddiqi (D) , Wafa Aftab (i) , 3 \\ Fahad Javaid Siddiqui (D) ,2,4 Luis Huicho, ${ }^{5,6}$ Roman Mogilevskii, ${ }^{7}$ \\ Qamar Mahmood, ${ }^{8}$ Peter Friberg, ${ }^{9,10}$ Fawad Akbari ${ }^{11}$
}

To cite: Bhutta ZA, Siddiqi S, Aftab W, et al. What will it take to implement health and healthrelated sustainable development goals? BMJ Global Health 2020;5:e002963. doi:10.1136/ bmjgh-2020-002963

Handling editor Seye Abimbola

Received 22 May 2020

Revised 30 July 2020

Accepted 3 August 2020
Check for updates

(c) Author(s) (or their employer(s)) 2020. Re-use permitted under CC BY-NC. No commercial re-use. See rights and permissions. Published by BMJ.

For numbered affiliations see end of article.

Correspondence to Dr Zulfiqar Ahmed Bhutta; zulfiqar.bhutta@aku.edu
In two previous publications, we have described and summarised key findings from the global systematic review and country consultations related to our assessment of the progress in implementing the health and health-related sustainable development goals (HHSDGs). Although it has been only 5 years but current evidence on the implementation of sustainable development goal (SDG) evaluations to date suggests that a vast majority of countries are off-target in relation to several outcome indicators ${ }^{1-3}$ and there are no clear strategies for integration across health and other sectors.

This paper will summarise the key learnings from this exercise and propose a strategy for enhancing integration and implementation of HHSDGs in low-income and middleincome countries (LMICs).

Our systematic review ${ }^{4}$ of the global evidence on the implementation of HHSDGs highlighted several important factors:

1. There are as yet no standardised metrics regarding progress and implementation globally that cover HHSDGs. The Institute of Health Metrics and Evaluation has developed and proposed a global SDG index, which has also been used to track progress $^{5}$; however, this has as yet not received widespread acceptance or recognition. At a global level, the focus on universal health coverage (UHC) by the WHO has influenced much country-level planning over the last few years but has little in terms of cross-sectoral actions.

2. A key factor behind progress in implementation of HHSDGs appears to be high-level political commitment at national level with alignment of the HHSDGs with existing development strategies and plans.

3. While multisectoral, integrated approaches were being adopted in most institutional
Summary box

- Five years into the sustainable development goa (SDG) era, the paradigm shift to integration and prevention needed to achieve health and health-related SDGs (HHSDGs) has not meaningfully materialised.

- Government leadership and multistakeholder planning are necessary for implementing HHSDGs without marginalising core health issues.

- Appropriate mechanisms are needed for consultation and integration, grounded in notions of social responsibility and sustainability, to bring together various actors including civic society, academia, think tanks and the private sector.

- While implementation and oversight of HHSDGs are mainly national, the global context in which it occurs cannot be neglected.

- Countries will need to significantly increase resource allocation to health and cross-sectoral initiatives to achieve the ambition of universal health coverage and addressing determinants of health.

set-ups, to-date evidence on the effectiveness of these approaches is limited.

4. Funding constraints appear to be a major challenge for many countries. HHSDGs are being financed through incorporation within existing funded plans and, in some places, through SDG-specific budgeting and tracking. In some instances, additional funding is being mobilised by increasing domestic taxation and subsidisation and by collaborating with development partners and UN agencies and in some instances, the private sector. However, these examples are few and far between.

5. Equity is being promoted by improving health service access for disadvantaged populations through UHC and especially, social insurance schemes but the overall evidence on successful approaches for equity promotion at scale and implementation at subnational level is limited. 
6. Key challenges to implementation of HHSDGs in countries included lack of coordination between different levels of government and with other stakeholders, limited mainstreaming of HHSDGs in subnational planning and budgeting, limited financial resources and hence high donor dependence. These are compounded by lack of disaggregated and reliable data allowing monitoring and accountability. Table 1 summarises the two measures of HHSDGs in place and their comparison.

In our analysis of country experiences and consultations, ${ }^{5}$ the above factors were borne out and the following key points were highlighted.

Despite the relatively short period since the launch of the SDGs, there was awareness of their importance to the national development agenda although in many countries of Africa and Asia, the ministries of health were still in the millennium development goal (MDG) mode. Most country participants also acknowledged that given the current situation in their countries and region, it may not be possible to achieve the 2030 agenda without accelerating implementation. This would need to be sustainable and intensive to achieve the HHSDGs targets by 2030 and, while challenging given current gaps in many countries, it was still possible.

To achieve these SDG targets, integrated implementation of HHSDGs would need to become central to current and future policies and strategies and not be seen as additional, external or vertical initiatives. Such implementation capacity would need to be strengthened subnationally to reduce equity gaps and reach marginalised populations.

This would need additional resources beyond current allocations. Given the need for adequate finances and extra funds needed for UHC, ${ }^{6}$ innovative financing strategies would be needed to mobilise domestic resources earmarked to health as a prerequisite for effective implementation of HHSDGs. To this end, domestic resource mobilisation and leverage would be key for sustainability, given indications that external development assistance for health will reduce over foreseeable future. ${ }^{7}$ Close engagement with development partners will be needed for financial and technical assistance but national governments should lead the SDG agenda

Monitoring, evaluation and accountability for HHSDGs should be strengthened and linked to measuring impact and equity indicators. The role of academia in this regard needs to be strengthened and robust follow-up procedures instituted. Of the range of indicators for progress, disaggregated information by population segments marginalised on the basis of race, ethnicity and gender is key. With improving methods for data analytics, geospatial monitoring of local disease burden and burden of disease is possible and can provide contextual information. ${ }^{8}$ However, these local analytics must be coupled with available national level information for policy relevant action.
Assessing gender-related differentials and assessing determinants thereof are a case in point and appear to be a major advance over the MDGs where gender was largely ignored and equity mainly considered through the lens of socioeconomic gradients. Addressing HHSDGs through a gender lens is imperative if one is to reduce pervasive gender-based inequities hampering progress in many countries.

\section{THE GLOBAL CONTEXT, HEALTH GOVERNANCE AND DETERMINANTS OF HEALTH}

The SDGs, and specifically SDG 3, that aim to ensure healthy lives and promote well-being for all, across all ages, require a paradigm shift in global health strategies. Our assessment suggests that this has not yet happened. No notable institutional, structural or financial reforms to global health governance to achieve the SDGs have taken place, and donors have not shifted their financing efforts. The one notable initiative launched at the cusp of the SDGs in July 2015 was the Global Financing Facility for addressing the continuum of maternal, child and adolescent health, ${ }^{9}$ but this still does not address many underlying social, political and commercial determinants of health. Doing so would require approaching SDG 3 holistically rather than by individual targets, diseases or programmes and moving well beyond the limited MDG health agenda. Existing institutions and financing instruments must be significantly reformed and if necessary, repurposed. ${ }^{10}$

Three key governance challenges are central for implementing the SDGs nationally and are especially applicable to HHSDGs: (1) cultivating collective action by creating inclusive decision spaces for stakeholder interaction across multiple sectors and scales; (2) making difficult trade-offs, focusing on equity, justice and fairness and (3) ensuring mechanisms exist to hold societal actors to account regarding decision-making, investment, action, and outcomes. ${ }^{11}$ Others have suggested that 'developed' countries providing bilateral support can sometimes impose their development aid priorities, which might not align with LMIC priorities. Hence, the need to strengthen and democratise global health governance. Nowhere is this more starkly evident than in the current situation with the blatant use of economic power by the USA to influence or defund the single global health oversight body, the WHO. There are additional concerns though about the influence that major corporations or their backed foundations/charities may have on the WHO and other UN agencies. Notwithstanding the dysfunction in a diverse member state-based system of global health decision-making process, democratisation of global health governance would need this inclusion as well as the global civil society's engagement in a transparent manner. This is especially so given the huge agenda and the right-based approach that that HHSDGs represent. 
Table 1 Health and health-related SDG indicators - WHO vs IHME reporting

\begin{tabular}{lclrll} 
& & & \multicolumn{3}{c}{ IHME } \\
S no & SDG target & Indicator & WHO/SDG report & estimates & Var \\
\hline 1 & 2.2 & Child stunting & 22.2 & 28.7 & - \\
2 & 2.2 & Child wasting & 7.5 & 8.0 & - \\
3 & 2.2 & Child overweight & 5.6 & 15.9 & W
\end{tabular}

Variations/gaps

\begin{tabular}{|c|c|c|c|c|c|}
\hline & & & & & $\begin{array}{l}\text { IHME measures for } 2-4 \text { years age } \\
\text { group }\end{array}$ \\
\hline 4 & 3.1 & $\begin{array}{l}\text { Maternal mortality ratio (per } \\
100000 \text { livebirths) }\end{array}$ & 216 & 145 & - \\
\hline 5 & 3.1 & $\begin{array}{l}\text { Births attended by skilled health } \\
\text { personnel (\%) }\end{array}$ & 78 & 80.1 & $\begin{array}{l}\text { WHO figure from } 2017 \text { report as not } \\
\text { reported in } 2018 \text {. }\end{array}$ \\
\hline 6 & 3.2 & $\begin{array}{l}\text { Neonatal mortality (per } 1000 \\
\text { livebirths) }\end{array}$ & 18.6 & 18.6 & - \\
\hline 7 & 3.2 & $\begin{array}{l}\text { Under-five mortality (per } 1000 \\
\text { livebirths) }\end{array}$ & 40.8 & 43.3 & - \\
\hline 8 & 3.3 & $\begin{array}{l}\text { HIV incidence (new HIV infections } \\
\text { per } 1000 \text { uninfected population) }\end{array}$ & 0.26 & 0.3 & - \\
\hline 9 & 3.3 & $\begin{array}{l}\text { Tuberculosis incidence (per } \\
100000 \text { population) }\end{array}$ & 140 & 139.6 & - \\
\hline
\end{tabular}

$\begin{array}{llllll}10 & 3.3 & \text { Malaria incidence } & 90.8 & 31.8 & \text { WHO measures malaria incidence per }\end{array}$
1000 at-risk population, while IHME measures age-standardised rate of cases per 1000 population

$\begin{array}{lllll}11 & 3.3 & \text { Hepatitis B incidence } & 1.30 & 2123.8 \\ 12 & 3.3 & \begin{array}{l}\text { Neglected Tropical Diseases } \\ \text { (NTDs) }\end{array} & 1499735642 & 24\end{array}$

WHO measures HBsAg prevalence in children under-five (\%) while IHME measures age-standardised rate of incidence/100 000

(NTDs)

WHO reports number of people requiring interventions against NTDs while IHME reports age-standardised prevalence of the sum of 15 NTDs (\%)

\begin{tabular}{|c|c|c|c|c|c|}
\hline 13 & 3.4 & NCD mortality & 18.3 & 382.7 & $\begin{array}{l}\text { WHO measures probability of dying } \\
\text { from any of CVD, cancer, diabetes, } \\
\text { CRD between age } 30 \text { years and exact } \\
\text { age } 70 \text { years (\%) while IHME reports } \\
\text { age-standardised death rate due to } \\
\text { CVD, cancer, diabetes and CRD in } \\
\text { age } \\
30-70 \text { years per } 100000 \text { population }\end{array}$ \\
\hline 14 & 3.4 & $\begin{array}{l}\text { Suicide mortality rate (per } 100000 \\
\text { population) }\end{array}$ & 10.6 & 10.0 & - \\
\hline 15 & 3.5 & Alcohol use & 6.4 & 11.6 & $\begin{array}{l}\text { WHO reports total alcohol per capita } \\
\text { ( } \geq 15 \text { years of age) consumption (litres } \\
\text { of pure alcohol) while IHME measures } \\
\text { risk-weighted prevalence of alcohol } \\
\text { consumption as measured by the } \\
\text { summary exposure value or alcohol } \\
\text { use }\end{array}$ \\
\hline 16 & 3.6 & Road traffic mortality (per 100 000) & 17.4 & 16.1 & - \\
\hline 17 & 3.7 & $\begin{array}{l}\text { Adolescent birth rate (per } 1000 \\
\text { women) }\end{array}$ & 43.9 & 21.7 & $\begin{array}{l}\text { WHO measures in women aged } \\
15-19 \text { years while IHME measures in } \\
\text { those } 10-19 \text { years of age }\end{array}$ \\
\hline
\end{tabular}

$18 \quad 3.7$

Family planning coverage

$77.4 \quad 75.7$

-

(proportion of married or in-union

WRA who have their need for FP

satisfied with modern methods

(\%))

Continued 
Table 1 Continued

\begin{tabular}{|c|c|c|c|c|c|}
\hline S no & SDG target & Indicator & WHO/SDG report & $\begin{array}{l}\text { IHME } \\
\text { estimates }\end{array}$ & Variations/gaps \\
\hline 19 & 3.8 & $\begin{array}{l}\text { UHC coverage-service coverage } \\
\text { index (RMNCH, infectious } \\
\text { diseases, NCDs) }\end{array}$ & 64 & 67.7 & - \\
\hline 20 & 3.9 & Mortality due to air pollution & 114.1 & 55.6 & $\begin{array}{l}\text { Both WHO and IHME measure as } \\
\text { age-standardised mortality rate } \\
\text { attributed to household and ambient } \\
\text { air pollution } \\
\text { (per } 100000 \\
\text { population) }\end{array}$ \\
\hline 21 & 3.9 & $\begin{array}{l}\text { Mortality due to unsafe water, } \\
\text { sanitation and hygiene (per } 100 \\
\text { 000) }\end{array}$ & 11.7 & 35.7 & $\begin{array}{l}\text { IHME reports theirs as 'age } \\
\text { standardised' while WHO does not }\end{array}$ \\
\hline 22 & 3.9 & $\begin{array}{l}\text { Mortality due to unintentional } \\
\text { poisoning (per } 100 \text { 000) }\end{array}$ & 1.4 & $\begin{array}{l}1.0 \text { (age- } \\
\text { standardised } \\
\text { death rate per } \\
100000)\end{array}$ & $\begin{array}{l}\text { IHME reports theirs as 'age } \\
\text { standardised' while WHO does not }\end{array}$ \\
\hline 23 & 3.a & $\begin{array}{l}\text { Tobacco use (age standardised } \\
\text { prevalence) } \%\end{array}$ & 20.2 ( $\geq 15$ years) & 18.4 ( $\geq 10$ years) & $\begin{array}{l}\text { WHO measures for } \geq 15 \text { years while } \\
\text { IHME measures for } \geq 10 \text { years }\end{array}$ \\
\hline 24 & 3.b & Vaccine coverage & - & - & $\begin{array}{l}\text { WHO measures individual } \\
\text { vaccine coverage (DPT, Measles, } \\
\text { Pneumococcal Conjugate) and } \\
\text { IHME is reporting coverage of } \\
\text { eight vaccines as coverage of eight } \\
\text { vaccines among target populations }\end{array}$ \\
\hline 25 & 6.1 & $\begin{array}{l}\text { Access to safely managed drinking } \\
\text { water source (\%) }\end{array}$ & 71 & - & Not reported by IHME \\
\hline 26 & 6.2 & $\begin{array}{l}\text { Access to safely managed } \\
\text { sanitation }(\%)\end{array}$ & 39 & - & Not reported by IHME \\
\hline 27 & 7.1 & Clean household energy (\%) & 59 & - & Not reported by IHME \\
\hline 28 & 13.1 & $\begin{array}{l}\text { Mortality due to conflict (per } 100 \\
\text { 000) }\end{array}$ & 2.5 & 1.9 & - \\
\hline
\end{tabular}

Sources: World health statistics 2018: monitoring health for the SDGs, sustainable development goals. Geneva: World Health Organization; 2018. Licence: CC BY-NC-SA 3.0 IGO. Measuring progress from 1990 to 2017 and projecting attainment to 2030 of the health-related sustainable development goals for 195 countries and territories: a systematic analysis for the Global Burden of Disease Study 2017. GBD 2017 SDG Collaborators*. Lancet 2018; 392: 2091-138.

CRD, Chronic respiratory disease; CVD, cardiovascular disease; DPT, diphtheria, pertussis, and tetanus(vaccine); FP, Family planning; HBsAg, Hepatitis B surface antigen; HIV, human immunodeficiency viruses; IHME, Institute for Health Metrics and Evaluation; NCD, Non-communicable disease; NTD, Neglected Tropical Diseases; RMNCH, reproductive, maternal, newborn and child health; SDGs, sustainable development goals; UHC, universal health coverage; WHO, World Health Organization; WRA, women of reproductive age.

What should then be the way forward given pragmatic constraints and ground realities in many countries? Clearly, ministries of health and nutrition have to prioritise the health and nutrition agenda enshrined in SDG 2 and 3. However, given the context of global priorities, it is important to underscore many issues that transcend disciplinary silos and impact health and development outcomes. To illustrate, two areas of global priority that have emerged given their impact on populations and health include climate change and the role that unfettered urbanisation and changing habitats play in increasing risks of infectious diseases. The link between climate change and environmental health globally and its impact on health outcomes is well recognised and should be an issue that all health professionals have to engage in. ${ }^{12}$ Deleterious effect of climate change on economic productivity and human capacity is a risk to sustainable development. Climate change-related risks-such as droughts, extreme weather events, changing disease patterns as well as water scarcity and air pollution-need active mitigation and adaptation-skills, capacities and funds. The global crisis of nutrition can also be tackled effectively through a sustainable food systems approach-promotion of locally available, affordable, diversified nutritious foods, as a strategy promoting environmental sustainability as well as prevention of overweight and obesity. ${ }^{13}$

How has the world changed in the few months since the series of consultations around HHSDGs, the last being in January 2020 in Islamabad. The huge impact of climate change on health and well-being was evident with unprecedented air pollution levels in major cities of South Asia 
such as Delhi and Lahore, ${ }^{14}{ }^{15}$ and the unprecedented floods in Mozambique. ${ }^{16}$ The recent large-scale wild fires in Australia, California and the Amazon rainforest, their impact on living conditions and air quality as well as health system constraints to address these issues, ${ }^{17} 18$ are remarkable examples of how linked these agendas are. The concepts of 'One-Health', defined as 'the collaborative efforts of multiple disciplines working locally, nationally and globally, to attain optimal health for people, animals and our environment ${ }^{19}$ are clearly important. ${ }^{20}$ With changing lifestyles, urbanisation and population transitions, there are increasing risks of animal to human transmission of microorganisms. The recent outbreaks of Ebola, MERS and Zika viruses and now the global spread of the SARS-CoV-2 are examples of these increased vulnerabilities and the interconnectedness of SDGs. The global COVID-19 pandemic has led to the first known closure of the global economy, travel and unprecedented restrictions on social mixing. Ministries of health are beginning to realise how interconnected various sectors are and the importance of the ecosystem we live in and the enormous inequities that we face in health systems globally in their capacities to respond to crises.

There are additional global level considerations and drivers that must be taken into account as we develop prioritisation criteria and actions for implementing HHSDGs. Global north-south equities are products of historical trends whose drivers continue to be operative today as well. These include trade laws, indebtedness and global power structures governing the political and economic spheres within which global health issues play out-for example, climate change. To illustrate while the global north benefited from industrialisation and emissions, global south stands to lose the most from the consequences. ${ }^{21} 22$ To-date, formal support mechanism for LMICs in adapting to and mitigating the effects of climate change is few and far between. ${ }^{23}$ There is the continuing need for effective mechanisms to tackle global inequality keeping in mind the historical basis and contemporary drivers of inequality (eg, trade laws that limit access to medicines and commodities) as well as the role of global corporations and the International Monetary Fund that often promotes structural adjustments at the cost of poverty alleviation. Eliminating income poverty and disparities will need economic reforms in countries but also bold moves such as debt forgiveness or restructuring, without which many LMICs will never recover from the COVID-19 pandemic-related economic devastation.

The HHSDGs offer enormous opportunities for collaboration and partnerships. While there is the need for south-south learning and cooperation, we must underscore the potential supportive role of 'developed' countries in supporting LMICs in enhancing local capacities and systems of implementation. Global cooperation and solidarity should be at the heart of SDG implementation and SDGs could serve as an important conduit for sustainable development in LMICs rather than aid dependency.
We need innovative measures of assessment of economic development and poverty that go beyond just GDP and take into account inequality, human well-being and the environmental and climate-related consequences of unfettered economic development and utilisation of natural resources. These are issues that seem to galvanise much of the youth and younger generation in ways that offers hope for the future. Health leaders and the health sector must play a central role in this global campaign to make our planet a better place for future generations rather than watch from the margins.

\section{Role of the private sector in SDGs}

Under the new SDG agenda businesses, governments and civil society actors are equally called on to pursue a more sustainable path forward. Many assert that the private sector has particular strengths that can be brought to bear in delivering on the SDGs, including innovation, responsiveness, efficiency and provision of specific skills and resources. This was clearly articulated in our consultative process in countries and regional meetings. A new paradigm in development thinking is needed that recognises the centrality of private enterprise in pursuit of the development agenda-and vice versa. ${ }^{24}$

A legitimate counterargument has questioned if profitmotivated businesses could really make a meaningful contribution to achievement of the SDGs or are more likely to see 'business as usual', which results in greater profits for some, and lost opportunities for many. For all the rhetoric regarding the potential of the private sector to transform development, there are serious impediments to this being the transformative process that requires a thorough analysis and propose options that are a win-win for everyone.

Private companies need to develop business models that are imbued with social values and notions of responsibility and that seek commercial success alongside more sustainable approaches and positive development outcomes. $^{24} 25$ This process ideally depends on active engagement of both the public and the private sectors. For this to happen, the national regulatory and policy frameworks should enable business and industry to advance sustainable development initiatives considering the importance of their corporate social responsibility and responsible business practices. Despite commitment from all partners, the mechanisms for leveraging the role and contribution of the private sector particularly to tackle inequities have yet to be worked out.

\section{THE WAY FORWARD}

Given the evidence to-date, what might one conclude as key actions needed in countries and where physicians and academics could contribute to the process? We put forward a series of actions and cross-cutting activities that could be considered in LMICs as prerequisites for creating and enabling an environment for implementing HHSDGs. 
First and foremost, there must be the political will to prioritise SDGs and especially the HHSDGs within countries. To date, 193 countries of the world have signed up to the vision 2030 agenda and key indicators have been developed after much technical background work and consultations. ${ }^{26}$ However, there are no universal agreed set of criteria and measurements for HHSDGs. The UN system generates periodic progress reports on $\mathrm{SDGs}^{1}$ and so does the Institute for Health Metrics and Evaluation (IHME), ${ }^{27}$ and while some estimates are comparable, there are significant differences between these two assessments (table 1)

Given the normative role of the WHO, it was expected that it would play a lead role in the development of consensus on key HHSDG indicators and progress. However, this has become secondary with the current focus at WHO on UHC coverage and the development of the UHC index ${ }^{28}$ as the main measure of progress within health. While an important initiative in its own right, it fails to take into account the multisectoral linkages across the HHSDGs. The recent Lancet Commission on Child Health is an example of integrating measures of child health and developmental outcomes with the important investments needed for environmental health and social protection. ${ }^{29}$

There is the need for adequate financing. An additional challenge within the existing proposals for UHC is the lack of clarity on processes for multisectoral collaboration and mechanisms for integrated implementation and fiscal mechanisms to catalyse the process. Within just a few months, trillions of dollars have been mobilised to save western economies whereas corresponding investments in addressing some of the root causes of the problem such as 'one health' and climate change have been few and far little.

In specific terms, we make the following five recommendations for implementing HHSDGs. These are not prescriptive but are supposed to prepare the ground for further deliberation:

1. Stewardship: Government leadership and multisectoral planning are critical for implementing HHSDGs with the proviso that given core health issues should not be marginalised in the context of multisectoral planning. More specifically, we would underscore the important role that individual political leaders and celebrity champions play in this regards. Given the slow progress noted in several evaluations, including ours, this leadership will be critical in order to allow for a full decade of intensive implementation of HHSDGs till 2030. Policy makers/implementers should pay attention to appropriate capacities at national and subnational levels, which support multisectoral and multistakeholder work. This process should include structural reforms and convening platforms such as Planning and Development Ministries. These are usually led by head of state but linked to provincial or lower level engagement in devolved health systems. It is critical that that HHSDGs be central to and well integrated within existing and future policies strategies and not be seen as 'add on', external or vertical initiatives.

2. Engagement: There need to be clear mechanisms for consultation and integration across various sectors especially with civic society and academia. These sectors working together can bring critical pressure to bear and secure resources for evidence-based action and to link to policy makers. While there are several possible mechanisms to accomplish this, the value of think tanks in affecting this change and advocacy is well recognised. ${ }^{30}$ These think tanks, especially the academic centres therein, could also play a major role in monitoring and evaluation and accountability and contribute to participatory governance with inclusion of various civil society actors and disadvantaged and minority populations. Given the paucity of high-quality evidence around models for implementation, these think tanks could also support implementation research and models of research to inform global policy.

3. Implementation: It is important to translate political commitment to HHSDGs into effective programmes that benefit common people. Implementation capacities must be strengthened at subnational and district levels with a focus on reaching those in greatest need, especially in marginalised populations. There must be appropriate institutional arrangements, subject to political, social and cultural contexts, that reflect policy coherence across sectors. One can envisage multisectoral structures with health at the centre, with the focus on processes of collaborative governance across sectors. There must be an equity focus with gender equality at its core and that also predicates the need for adequate representation of women in leadership positions at every level.

4. Financing: Implementing HHSDGs in letter and spirit will require new and additional resources as merely moving funds from within health or other sectors to HHSDGs does not solve the resource gap. Countries will need to significantly increase resource allocation to health to achieve the ambition of UHC and cross-sectoral initiatives. This will need thinking through the role of the private sector as well as engagement with development partners for focused and strategic financing. There is little evidence that this is happening so far and the global economic crisis in the wake of the COVID-19 pandemic makes it even more unlikely that major extra resources will be available anytime soon. While some of this can indeed be achieved through smart financing and sharing of resources, there is a need for innovative financing strategies to mobilise domestic resources for health.

5. Accountability: We need to track what we are doing and the gaps in our knowledge of progress. The monitoring and evaluation of HHSDGs should be strengthened and linked to measuring performance, equity and accountability. In addition to the potential role of research and academic bodies, this will need further strengthening of statistical systems with ability to produce reliable, timely, disaggregated data including better quality and use of routine administrative data. If there are lessons from the COVID-19 pandemic that engulfs us, they are exactly that. Countries with strong information systems and accurate data were able to respond with alacrity and flatten the curve. Within the last decade of SDGs, more of the same will not work, at least we need to rapidly increase 
our capacity to monitor trends, feedback information on key gaps and opportunities for action.

\section{Author affiliations}

${ }^{1}$ Division of Women and Child Health, Aga Khan University, Karachi, Pakistan ${ }^{2}$ Centre for Global Child Health, Hospital for Sick Children SickKids Learning Institute, Toronto, Ontario, Canada

${ }^{3}$ Community Health Sciences Department, Aga Khan University Medical College Pakistan, Karachi, Sindh, Pakistan

${ }^{4}$ The Academia, Duke-NUS Medical School, Singapore

${ }^{5}$ Centro de Investigación en Salud Materna e Infantil, Universidad Peruana Cayetano Heredia, Lima, Lima, Peru

${ }^{6}$ Pediatrics, Facultad de Medicina de San Fernando, Universidad Nacional Mayor de San Marcos, Lima, Peru

${ }^{7}$ Institute of Public Policy and Administration, University of Central Asia, Bishkek, Kyrgyzstan

${ }^{8}$ International Development Research Centre, Ottawa, Ontario, Canada

${ }^{9}$ Department of Physiology, Institute of Medicine, Sahlgrenska Academy, University of Gothenburg, Gothenburg, Sweden

${ }^{10}$ Swedish Institute for Global Health Transformation (SIGHT), Royal Swedish

Academy of Sciences, Stockholm, Sweden

${ }^{11}$ Aga Khan Foundation Canada, Ottawa, Ontario, Canada

Twitter Fahad Javaid Siddiqui @fjsepi

Contributors $Z A B$ conceptualised the study. ZAB synthesised and conducted the analysis with contribution from all co-authors. ZAB drafted the manuscript and all co-authors critically revised it. All authors approved the final version.

Funding This study was funded by International Development Research Centre, Canada.

Competing interests None declared.

Patient and public involvement Patients and/or the public were not involved in the design, or conduct, or reporting, or dissemination plans of this research.

Patient consent for publication Not required.

Provenance and peer review Not commissioned; internally peer reviewed.

Data availability statement All data relevant to the study are included in the article.

Open access This is an open access article distributed in accordance with the Creative Commons Attribution Non Commercial (CC BY-NC 4.0) license, which permits others to distribute, remix, adapt, build upon this work non-commercially, and license their derivative works on different terms, provided the original work is properly cited, appropriate credit is given, any changes made indicated, and the use is non-commercial. See: http://creativecommons.org/licenses/by-nc/4.0/.

\section{ORCID iDs}

Zulfiqar Ahmed Bhutta http://orcid.org/0000-0003-0637-599X

Sameen Siddiqi http://orcid.org/0000-0001-8289-0964

Wafa Aftab http://orcid.org/0000-0001-5040-5215

Fahad Javaid Siddiqui http://orcid.org/0000-0002-9046-5105

\section{REFERENCES}

1 United Nations. Sustainable development goals report, 2019. Available: https://unstats.un.org/sdgs/report/2019/The-SustainableDevelopment-Goals-Report-2019.pdf

2 GBD 2016 SDG Collaborators. Measuring progress and projecting attainment on the basis of past trends of the health-related sustainable development goals in 188 countries: an analysis from the global burden of disease study 2016. Lancet 2017;390:1423-59.

3 GBD 2017 SDG Collaborators. Measuring progress from 1990 to 2017 and projecting attainment to 2030 of the health-related sustainable development goals for 195 countries and territories: a systematic analysis for the global burden of disease study 2017. Lancet 2018:392:2091-138.

4 Aftab W, Siddiqui F, Tasic H, et al. Implementation of health and health-related sustainable development goals: progress, challenges and opportunities. A systematic literature review.

5 Siddiqi S, Aftab W, Siddiqui F, et al. Global strategies and local implementation of health and health related SDGs: lessons from consultation in countries across five regions.
6 World Health Organization. Universal health coverage (UHC) fact sheet, 2019. Available: t.ly/wvKD

7 Bhutta ZA, Aimone A, Akhtar S. Climate change and global child health: what can paediatricians do? Arch Dis Child 2019;104:417-8.

8 Alsan M, Xing A, Wise P, et al. Childhood illness and the gender gap in adolescent education in low- and middle-income countries. Pediatrics 2017;140. doi:10.1542/peds.2016-3175. [Epub ahead of print: 26 Jun 2017].

9 Claeson $\mathrm{M}$. The global financing facility-towards a new way of financing for development. Lancet 2017;389:1588-92.

10 Marten R, Kadandale S, Nordström A, et al. Shifting global health governance towards the sustainable development goals. Bull World Health Organ 2018;96:798-798A.

11 Bowen KJ, Cradock-Henry NA, Koch F, et al. Implementing the "sustainable development goals": towards addressing three key governance challenges-collective action, trade-offs, and accountability. Curr Opin Environ Sustain 2017;26-27:90-6.

12 Willett W, Rockström J, Loken B, et al. Food in the Anthropocene: the EAT-Lancet Commission on healthy diets from sustainable food systems. Lancet 2019;393:447-92.

13 NCD Risk Factor Collaboration (NCD-RisC). Worldwide trends in body-mass index, underweight, overweight, and obesity from 1975 to 2016: a pooled analysis of 2416 population-based measurement studies in 128.9 million children, adolescents, and adults. Lancet 2017;390:2627-42.

14 Ali M, Athar M. Impact of transport and industrial emissions on the ambient air quality of Lahore City, Pakistan. Environ Monit Assess 2010;171:353-63.

15 Maji S, Ghosh S, Ahmed S. Association of air quality with respiratory and cardiovascular morbidity rate in Delhi, India. Int $J$ Environ Health Res 2018;28:471-90.

16 Kahn R, Mahmud AS, Schroeder A, et al. Rapid forecasting of cholera risk in Mozambique: translational challenges and opportunities. Prehosp Disaster Med 2019;34:557-62.

17 Cousins S. Bushfires expose weaknesses in Australia's health system. Lancet 2020;395:175-6.

18 James SL, Lucchesi LR, Bisignano C, et al. Epidemiology of injuries from fire, heat and hot substances: global, regional and national morbidity and mortality estimates from the global burden of disease 2017 study. Inj Prev 2019. doi:10.1136/injuryprev-2019-043299. [Epub ahead of print: 18 Dec 2019].

19 American Veterinary Medical Association. One health initiative task force. one health: a new professional imperative, 2008. t.ly/1eNO

20 Ryu S, Kim BI, Lim J-S, et al. One health perspectives on emerging public health threats. J Prev Med Public Health 2017;50:411-4.

21 Bathiany S, Dakos V, Scheffer M, et al. Climate models predict increasing temperature variability in poor countries. Sci Adv 2018;4:eaar5809.

22 Lloyd SJ, Bangalore M, Chalabi Z, et al. A Global-level model of the potential impacts of climate change on child stunting via income and food price in 2030. Environ Health Perspect 2018;126:97007.

23 Daoud A, Halleröd B, Guha-Sapir D. What is the association between absolute child poverty, poor governance, and natural disasters? a global comparison of some of the realities of climate change. PLoS One 2016;11:e0153296.

24 Scheyvens R, Banks G, Hughes E. The private sector and the SDGs: the need to move beyond 'business as usual'. J Sustain Dev 2016;24:371-82.

25 National Academies of Sciences, Engineering, and Medicine, Health and Medicine Division, Board on Global Health, Forum on Public-Private Partnerships for Global Health and Safety. Engaging the private sector and developing partnerships to advance health and the sustainable development goals: proceedings of a workshop series. Washington (DC): National Academies Press (US), 2017.

26 United Nations Sustainable Development Goals. Transforming our world: the 2030 agenda for sustainable development. Available: t.ly/ vZNA7

27 Institute of Health Metrics. The global goals (SDGs). Available: t.ly/ WTif

28 Clark H, Coll-Seck AM, Banerjee A, et al. A future for the world's children? A WHO-UNICEF-Lancet Commission. Lancet 2020;395:605-58.

29 Bennett S, Corluka A, Doherty J, et al. Influencing policy change: the experience of health think tanks in low- and middle-income countries. Health Policy Plan 2012;27:194-203.

30 Stenberg K, Hanssen O, Edejer TT-T, et al. Financing transformative health systems towards achievement of the health sustainable development goals: a model for projected resource needs in 67 low-income and middle-income countries. Lancet Glob Health 2017;5:e875-87. 